\title{
Comparison of the incidence of colorectal cancer in young adults between the USA and Europe
}

We read with interest the article titled 'Increasing incidence of colorectal cancer in young adults in Europe over the last 25 years' by Vuik et al, in which they analysed trends in colorectal cancer (CRC) among young adults (20-49 years old) and found that CRC incidence is increasing among young adults in Europe. ${ }^{1}$ We have found that the incidence of CRC in young adults in Europe is significantly different from that in the USA. ${ }^{2}$ Therefore, we analysed the incidence of CRC in young adults with data from the Surveillance, Epidemiology and End Results database (from 1990 to 2016, a total of 78295 cases, aged from 20 to 49 years) by the Joinpoint regression method and compared it with the results from Europe.

We found that the incidence of CRC in young adults in the USA increased annually, with an annual per cent change (APC) of $4.3 \%$ in the age group of $20-29$ years, $2.47 \%$ in the age group of $30-39$ years and $1.8 \%$ in the age group of $40-49$ years (figure $1 \mathrm{~A}-\mathrm{C}$ ). Although the incidence rate was increasing, the mortality rate had not changed significantly, which may be related to young adults presenting with more local or regional disease. ${ }^{3-5}$ We know little about the indications for colonoscopy in young adults, but studies have shown increases in colonoscopy use that parallel the incidence of CRC in young adults, which could explain the increasing rates of local or regional disease. ${ }^{4}$ Conversely, some studies reported that CRC in young adults was more aggressive and resulted in worse survival, perhaps because they had more mucinous and signet ring cell histology, had a family history of CRC and were less likely to be screened. ${ }^{6}$ In addition, we found that while the incidence of CRC in Europe was 

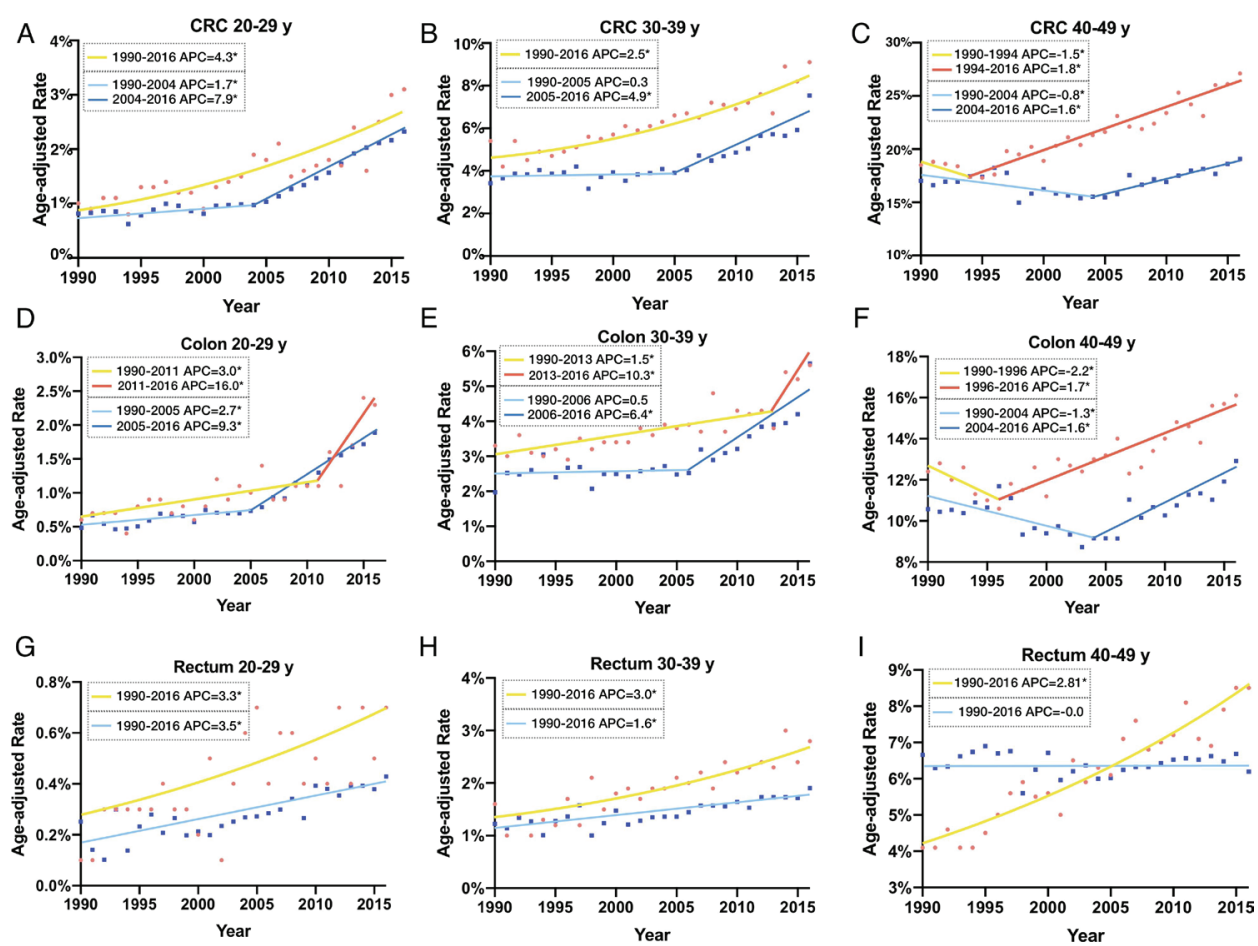

Figure 1 (A) The APC in patients with CRC aged 20-29 years old in the USA is 4.3\%. In Europe, the APC was $1.7 \%$ from 1990 to 2004 and $7.9 \%$ from 2005 to 2016. (B) The APC in patients with CRC aged 30-39 years old in the USA is $2.47 \%$. The APC in Europe from 1990 to 2005 was $0.3 \%$, with an annual increase of $4.9 \%$ from 2005 to 2016 . (C): The APC in patients with CRC aged $40-49$ years old in the USA was reduced by $1.5 \%$ between 1990 and 1994 but increased by an average of $1.8 \%$ per year from 1994 to 2016. In Europe, the APC decreased by $0.8 \%$ between 1990 and 2004 but increased by $1.6 \%$ per year thereafter. (D) The APC in patients with CRC aged 20-29 years old in the USA from 1990 to 2011 was $3.0 \%$ and was as high as $16.0 \%$ from 2011 to 2016. The APC in Europe was 2.7\% from 1990 to 2005 and 9.3\% from 2005 to 2016. (E) The APC in patients with colon cancer in the age group of 30-39 years in the USA was 1.5\% from 1990 to 2013 and reached 10.3\% from 2013 to 2016. The APC in Europe from 1990 to 2006 was $0.5 \%$, and from 2005 to 2016, it was 6.4\%. (F) The APC in patients with colon cancer aged 40-49 years in the USA decreased by $2.2 \%$ per year from 1990 to 1996 and increased by an average of 1.7\% per year from 1999 to 2016 . The APC in Europe from 1990 to 2004 was $-1.3 \%$, with an average annual rate of $1.6 \%$ from 2004 to 2016. (G) The incidence rates of rectal cancer in patients aged 20-29 years old in the USA and Europe are increasing by 3.3\% and 3.5\% per year, respectively. $(\mathrm{H})$ The APC in rectal cancer in the USA among those aged 30-39 year is 3.03\%, compared with $1.6 \%$ in Europe. (I) In the USA, rectal cancer in patients aged $40-49$ years is increase at a rate of $2.8 \%$ per year, while the incidence in Europe remains stable. *: APC is significantly different from zero. '- yellow' and '- orange' line: APC in incidence rates in the USA, 1990-2016. ' yellow' and '• orange' dot: aged-adjusted rates in the USA. '- dark blue' and '- light blue' line: APC in incidence rates in Europe, 1990-2016. '• dark blue' and "• light blue' dot: aged-adjusted rates in Europe. APC, annual per cent change; CRC, colorectal cancer.

also increasing in young adults, the rate of increase in the USA was significantly higher than that in Europe (figure $1 \mathrm{~A}-\mathrm{C}$ ). This may be because the USA has a significantly higher incidence of obesity than Europe. In 2012 , the obesity rate in the USA was $35 \%$, and it was as high as $39.8 \%$ in 2016 ; however, in Europe, the obesity rate was approximately $15.9 \%$ in $2014 .^{7} \mathrm{Next}$, we observed that the APC in the USA ranged from $3.0 \%$ (1990-2011) to 16.0\% (2011$2016)$ in the age group of 20-29 years (figure 1D), and from 1.5\% (1990-2013) to $10.3 \%$ (2013-2016) in the age group of 30-39 yearss (figure 1E). The trend in the incidence of CRC in patients aged 20-39 years became steeper in 2011-2013. This may be related to the US government's implementation of the Affordable Care Act in 2010, after which the proportion of adults aged 19-34 years who were uninsured reduced from $28 \%$ in 2013 to $18 \%$ in 2016. ${ }^{8}$ The incidence of CRC in both the USA and Europe is growing the fastest in the age group of 20-29 years and the slowest in the age group of 40-49 years (figure $1 \mathrm{~A}-\mathrm{C}$ ). This is likely because the incidence of CRC in young adults is closely related to family history. ${ }^{9}$ The incidence rate of rectal cancer in the age group of 40-49 years in Europe is stable (figure 1I), which may be related to antibiotic use, periodontal disease and $\mathrm{pH}$ levels across the entire colorectum. ${ }^{4}$

In summary, the incidence of CRC in young adults in the USA is significantly higher than that in Europe, and the specific reasons for this difference need to be studied in depth, which may help to take specific measures to reduce the incidence of CRC.

Ting Wei, ${ }^{1}$ Peng Luo, ${ }^{1}$ Xiaoli Zhang, ${ }^{1}$ Weiliang Zhu, ${ }^{1}$ Jian Zhang ${ }^{1}{ }^{1}$
Department of Oncology, Zhujiang Hospital, Southern Medical University, Guangzhou, China

Correspondence to Professor Jian Zhang, Guangzhou, China; blacktiger@139.comDr Peng Luo; luopeng@smu.edu.cn

Contributors Drafting of the manuscript: TW. Study concept and design: PL. Acquisition, analysis or interpretation of data: all authors. Critical revision of the manuscript for important intellectual content: all authors. Statistical analysis: PL and XZ. Study supervision: JZ.

Funding This work was supported by the National Natural Science Foundation of China (grant numbers 81672267,81772457 and 81871859) , the Province Natural Science Foundation of Guangdong (grant numbers 2016A030313632 and 2017A030313567) and Guangzhou science and technology project (grant number 201804010200).

Competing interests None declared.

Patient consent for publication Not required.

Provenance and peer review Not commissioned; internally peer reviewed. 


\section{(2) \\ OPEN ACCESS}

Open access This is an open access article distributed in accordance with the Creative Commons Attribution Non Commercial (CC BY-NC 4.0) license, which permits others to distribute, remix, adapt, build upon this work non-commercially, and license their derivative works on different terms, provided the original work is properly cited, appropriate credit is given, any changes made indicated, and the use is non-commercial. See: http://creativecommons.org/ licenses/by-nc/4.0/.

(c) Author(s) (or their employer(s)) 2020. Re-use permitted under CC BY-NC. No commercial re-use. See rights and permissions. Published by BMJ.

TW, PL, XZ and WZ contributed equally.

$\mathrm{PL}$ and $\mathrm{JZ}$ are joint senior authors.

\section{A Check for updates}

To cite Wei T, Luo P, Zhang X, et al. Gut 2020;69:1540-1542.

Received 30 June 2019

Revised 13 July 2019

Accepted 17 July 2019

Published Online First 31 July 2019

Gut 2020;69:1540-1542. doi:10.1136/

gutjnl-2019-319391

ORCID iD

Jian Zhang http://orcid.org/0000-0001-7217-0111

\section{REFERENCES}

1 Vuik FER, Nieuwenburg SAV, Bardou M, et al. Increasing incidence of colorectal cancer in young adults in Europe over the last 25 years. Gut 2019:68:1820-6.

2 Siegel RL, Fedewa SA, Anderson WF, et al. Colorectal cancer incidence patterns in the United States, 1974-2013. J Natl Cancer Inst 2017;109.

3 Teng A, Lee DY, Cai J, et al. Patterns and outcomes of colorectal cancer in adolescents and young adults. J Surg Res 2016;205:19-27.

4 Murphy CC, Wallace K, Sandler RS, et al. Racial disparities in incidence of young-onset colorectal cancer and patient survival. Gastroenterology 2019;156:958-65.

5 Murphy CC, Lund JL, Sandler RS. Young-onset colorectal cancer: earlier diagnoses or increasing disease burden? Gastroenterology 2017;152:1809-12.

6 Wang W, Chen W, Lin J, et al. Incidence and characteristics of young-onset colorectal cancer in the United States: an analysis of SEER data collected from 1988 to 2013. Clin Res Hepatol Gastroenterol 2019;43:208-15.

$7 \mathrm{Ng} \mathrm{M}$, Fleming T, Robinson M, et al. Global, regional, and national prevalence of overweight and obesity in children and adults during 1980-2013: a systematic analysis for the global burden of disease study 2013. Lancet 2014;384:766-81.

8 Collins SR, Gunja M, Doty MM, et al. Americans' experiences with ACA marketplace and Medicaid coverage: access to care and satisfaction: findings from the Commonwealth fund Affordable care act tracking survey, February-April 2016. Issue Brief 2016;14:1-18.

9 Rosato V, Bosetti C, Levi F, et al. Risk factors for young-onset colorectal cancer. Cancer Causes Control 2013;24:335-41. 